\title{
Synthesis and Characterization of OH-Terminated Poly(trimethylene carbonate)s by Alcohol-Initiated Ring-Opening Polymerization in Melt Bulk without Using Any Catalyst
}

\author{
Faquan $\mathrm{YU}^{\dagger}$ and Renxi ZHUO* \\ Department of Chemical Engineering, Hubei Key Laboratory of Novel Reactor and Green Chemical Technology, \\ Wuhan Institute of Chemical Technology, Wuhan 430074, Hubei, China \\ *Department of Chemistry, Wuhan University, Wuhan 430072, Hubei, China
}

(Received July 18, 2003; Accepted September 30, 2003)

\begin{abstract}
OH-terminated poly(trimethylene carbonate)s (OH-PTMC) were synthesized by ring-opening polymerization (ROP) of trimethylene carbonate (TMC) in the melt bulk in vacuo at $120^{\circ} \mathrm{C}$ using an alcohol such as benzyl alcohol, 1,4-butanediol, ethanol, isopropanol, or tertiary butanol as a respective initiator in the presence or in the absence of acid catalyst (e.g. trifluoroacetic acid (TFA)). The products were characterized by ${ }^{1} \mathrm{H}$ NMR and GPC. Experiments showed that TFA was not indispensable under the polymerization conditions and that the ROP conformed to a pseudoliving polymerization. The molecular weights of products can be predicted based on the monomer conversion and the molar ratio of monomer to initiator practically participating in the polymerization. It was also demonstrated that the alcohol ability to initiate the ROP increased in the following order: ethanol $>$ isopropanol $>t$-butanol whether using TFA or not. Part of isopropanol or $t$-butanol did not practically participate in the initiation step and the participating degree further decreased in the absence of TFA catalyst.

KEY WORDS Ring-opening Polymerization / Alcohol Initiation / Pseudoliving Polymerization / Poly(trimethylene carbonate) / Functionalized End Group /
\end{abstract}

Aliphatic polycarbonate, for example, poly(trimethylene carbonate) (PTMC), displays good biocompatibility, degradability by hydrolysis or enzyme and high elasticity at room temperature, and is one of the most important biodegradable polymers. ${ }^{1,2}$ Besides, OHterminated PTMC (OH-PTMC) is very useful in the synthesis of other biodegradable polymers. It can be used to initiate another comonomer to prepare multiblock copolymers. $\mathrm{OH}$ end group can be further transformed into other end groups to adjust the degradability, etc. ${ }^{3}$

Alcohol-initiated ring-opening polymerization (ROP) is a convenient method of choice for the preparation of $\mathrm{OH}$-terminated PTMC. ${ }^{1,3}$ This method was also used to synthesize $\mathrm{OH}$-terminated polyesters, such as polycaprolactone, poly(lactide-co-glycolide), or polylactide, etc. ${ }^{4-12}$ Several metal complexes have been usually chosen as catalysts, especially metal carboxylates and alkoxides, such as stannous octoate $\left(\mathrm{SnOct}_{2}\right)$ and aluminum isopropoxide. Herein, the alcohol is the real initiator whereas SnOct $_{2}$ acts as a Lewis acid catalyst to provide the ROP with a fast kinetics. ${ }^{13-15}$ However, these metal impurities remain in these materials and would result in an unpredicted trouble in body when these resulting materials were used as biomaterials though $\mathrm{SnOct}_{2}$ is a permitted food additive in numerous countries. ${ }^{16,17}$ On the other hand, considering the catalysis mechanism of Lewis acid of such metal complexes, trifluoroacetic acid (TFA) has been also chosen as a catalyst of the ROP of seven- or six-number cyclic carbonates in order to reduce the harmfulness of metal residue. ${ }^{18}$

In fact, in the absence of such catalysts, the ringopening reactions of seven-numbered cyclic carbonate also occurred. ${ }^{18}$ Dong reported that the conversion of monomers did not decrease when $\mathrm{SnOct}_{2}$ was used much less. ${ }^{4}$ Shiomi synthesized PCL-b-PEG-b-PCL triblock by the bulk ROP of $\varepsilon$-caprolactone initiated with hydroxy groups at both chain ends of PEG without any catalyst at $200{ }^{\circ} \mathrm{C} .{ }^{10}$ These observations show that a catalyst seems to be not indispensable in the ROP under suitable polymerization conditions.

Ideally, if no catalyst and no solvent were needed, the resulting PTMC would be pure and favor its applications as biomaterials. In the present study, we, on the ground of investigation of the necessity of TFA as a catalyst, synthesized $\mathrm{OH}$-terminated PTMC by the alcohol-initiated ROP of TMC in melt bulk without using any catalyst and any solvent.

\section{EXPERIMENTAL}

\section{Materials}

TFA was refluxed for $1 \mathrm{~h}$ over $\mathrm{P}_{2} \mathrm{O}_{5}$ then distilled. Benzyl alcohol was purified by distillation over $\mathrm{CaO}$. 1,4-butanediol was distilled under vacuum over

${ }^{\dagger}$ To whom correspondence should be addressed (Tel: 86-27-87195671, Fax: 86-27-87194465, E-mail: fqyu@public.wh.hb.cn). 
$\mathrm{KOH}$. Ethanol was pretreated as follows: $5 \mathrm{~mL}$ of ethanol (analytical grade) was first refluxed over magnesium and iodine for $1 \mathrm{~h}$ and then $70 \mathrm{~mL}$ of ethanol was added and refluxed for $30 \mathrm{~min}$ and distilled. Isopropanol was treated over $\mathrm{CaH}_{2}$ and then distilled. Tertiary butanol was treated over $\mathrm{CaH}_{2}$ overnight, filtered and then fractionally distilled.

1,3-Trimethylene carbonate (TMC) was synthesized according to the reported method. ${ }^{19}$ To a solution of 1,3-propanediol $(29.9 \mathrm{~g}, 0.393 \mathrm{~mol})$ and ethyl chloroformate $(85.4 \mathrm{~g}, 0.786 \mathrm{~mol})$ in $1800 \mathrm{~mL}$ tetrahydrofuran (THF) was added a solution of triethylamine $(84.0 \mathrm{~g}, 0.825 \mathrm{~mol})$ in THF $(198 \mathrm{~mL})$ dropwise at $0{ }^{\circ} \mathrm{C}$ over a period of $30 \mathrm{~min}$. The reaction mixture was stirred at room temperature for $2 \mathrm{~h}$. Precipitated triethylamine hydrochloride was filtered off, and the filtrate was concentrated under reduced pressure. The products was recrystallized repeatedly from THF and ether. Yield: $45 \%, \mathrm{mp}: 45^{\circ} \mathrm{C} .{ }^{1} \mathrm{HNMR}\left(\mathrm{CDCl}_{3}\right): \delta$ 2.14-2.17 (quint, $\left.-\mathrm{CH}_{2}-, 2 \mathrm{H}\right), 4.47\left(\mathrm{t},-\mathrm{OCH}_{2}-, 4 \mathrm{H}\right)$.

\section{Measurements}

Molecular weights $\left(\bar{M}_{\mathrm{n}}\right.$ and $\left.\bar{M}_{\mathrm{w}}\right)$ and the distributions $\left(\bar{M}_{\mathrm{w}} / \bar{M}_{\mathrm{n}}\right)$ were determined by gel permeation chromatography (GPC) on a Waters 2690D unit equipped with Shodex K802.5 and K805 with Shodex $\mathrm{K}-\mathrm{G}$ guard column, using chloroform as the eluent at a flow rate of $1.0 \mathrm{~mL} / \mathrm{min}$ at $30^{\circ} \mathrm{C}$. Calibration was carried out with polystyrene standards. ${ }^{1} \mathrm{H}$ NMR spectra were recorded on a NMR spectrometer Mercury300BB "mercury 300" in chloroform-d $\left(\mathrm{CDCl}_{3}\right)$ at ambient temperature. Tetramethylsilane (TMS) signal is taken as the zero chemical shift. IR spectra were measured using a Nicolet 420 FT-IR spectrometer. Melting points were measured by a micro meltingpoint apparatus.

\section{Polymerization}

The ROP of TMC initiated by an alcohol is illustrated in Scheme 1. All polymerization results are complied in Tables I to V. The ROP was carried out in the melt bulk. All reagents were used just after treated. A known amount of TMC was charged into a previously flamed and nitrogen-purged glass polymerization tube, containing a Teflon-coated magnetic stirring bar. Then an exhausting-refilling process was repeated three times with a $15 \mathrm{~s}$ nitrogen sweeping every $10 \mathrm{~min}$ exhausting at $60^{\circ} \mathrm{C}$. After the tube was cooled at room temperature, an alcohol and TFA (or an alcohol only) were added through a dried syringe under $\mathrm{N}_{2}$ atmosphere. The tube was degassed and sealed under vacuum within $60 \mathrm{~s}$ and immersed in a thermostated oil bath at $120^{\circ} \mathrm{C}$ with agitation. After the predetermined reaction time, the tube was broken

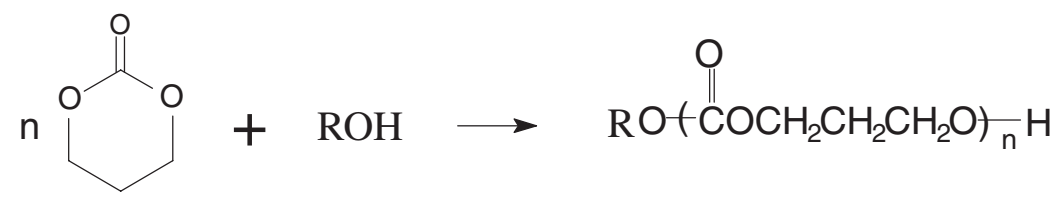

Scheme 1. Ring-opening polymerization of TMC initiated by alcohol.

Table I. The results of the ROP of TMC initiated by benzyl alcohol

\begin{tabular}{cccccccccc}
\hline Run & $\begin{array}{c}{[M] /[I]} \\
(\mathrm{mol} / \mathrm{mol})\end{array}$ & $\begin{array}{c}\text { TFA } \\
(\mu \mathrm{L})\end{array}$ & $\begin{array}{c}\text { Time } \\
(\mathrm{h})\end{array}$ & $\begin{array}{c}\mathrm{C} \% \\
(\%)\end{array}$ & $\bar{M}_{\mathrm{n}, \mathrm{th}}$ & $\bar{M}_{\mathrm{n}, \mathrm{GPC}}$ & $\bar{M}_{\mathrm{n}, \mathrm{NMR}}$ & $\bar{M}_{\mathrm{w}} / \bar{M}_{\mathrm{n}}$ & $\begin{array}{c}\alpha \\
(\%)\end{array}$ \\
\hline 1 & 63 & 4 & 48 & 76.0 & 4883 & 5255 & 5146 & 1.89 & 94.9 \\
2 & 28 & 0 & 48 & 93.5 & 2670 & 2875 & 2369 & 1.69 & 112 \\
\hline
\end{tabular}

$[M] /[I]$ : molar ratio of TMC to benzyl alcohol, C\%: TMC conversion, $\alpha=\bar{M}_{\mathrm{n}, \mathrm{th}} / \bar{M}_{\mathrm{n}, \mathrm{NMR}} \times 100 \%$, $\bar{M}_{\mathrm{n}, \mathrm{th}}=[M] /[I] \cdot M W_{\mathrm{TMC}} \cdot$ Conversion\%, the amount of TMC: $1000 \mathrm{mg}$.

Table II. The results of the ROP of TMC initiated by 1,4-butanediol

\begin{tabular}{cccccccccc}
\hline Run & $\begin{array}{c}{[M] /[I]} \\
(\mathrm{mol} / \mathrm{mol})\end{array}$ & $\begin{array}{c}\text { TFA } \\
(\mu \mathrm{L})\end{array}$ & $\begin{array}{c}\text { Time } \\
(\mathrm{h})\end{array}$ & $\begin{array}{c}C \\
(\%)\end{array}$ & $\bar{M}_{\mathrm{n}, \mathrm{h}}$ & $\bar{M}_{\mathrm{n}, \mathrm{GPC}}$ & $\bar{M}_{\mathrm{n}, \mathrm{NMR}}$ & $\bar{M}_{\mathrm{w}} / \bar{M}_{\mathrm{n}}$ & $\begin{array}{c}\alpha \\
(\%)\end{array}$ \\
\hline 3 & 56 & 4 & 48 & 97.1 & 5546 & 6757 & 6501 & 1.89 & 85.3 \\
4 & 73 & 4 & 48 & 98.0 & 7297 & 8999 & 7875 & 1.94 & 92.6 \\
5 & 126 & 4 & 48 & 97.7 & 12556 & 12074 & 11367 & 1.82 & 110.0 \\
6 & 75 & 0 & 48 & 89.2 & 6914 & 8028 & 7458 & 1.64 & 89.2 \\
7 & 125 & 0 & 48 & 94.0 & 11985 & 13120 & 13070 & 1.67 & 91.7 \\
8 & 175 & 0 & 48 & 94.4 & 16850 & 18248 & 16423 & 1.72 & 102.6 \\
\hline
\end{tabular}

$[M] /[I]$ : molar ratio of TMC to 1,4-butanediol alcohol, C\%: TMC conversion, $\alpha=\bar{M}_{\mathrm{n}, \mathrm{th}} / \bar{M}_{\mathrm{n}, \mathrm{NMR}} \times 100 \%$, $\bar{M}_{\mathrm{n}, \mathrm{th}}=[M] /[I] \cdot M W_{\mathrm{TMC}} \cdot$ Conversion\%, the amount of TMC: $1000 \mathrm{mg}$. 
Table III. The results of the ROP of TMC initiated by ethanol

\begin{tabular}{cccccccccc}
\hline Run & $\begin{array}{c}{[M] /[I]} \\
(\mathrm{mol} / \mathrm{mol})\end{array}$ & $\begin{array}{c}\text { TFA } \\
(\mu \mathrm{L})\end{array}$ & $\begin{array}{c}\text { Time } \\
(\mathrm{h})\end{array}$ & $\begin{array}{c}C \\
(\%)\end{array}$ & $\bar{M}_{\mathrm{n}, \mathrm{th}}$ & $\bar{M}_{\mathrm{n}, \mathrm{GPC}}$ & $\bar{M}_{\mathrm{n}, \mathrm{NMR}}$ & $\bar{M}_{\mathrm{w}} / \bar{M}_{\mathrm{n}}$ & $\begin{array}{c}\alpha \\
(\%)\end{array}$ \\
\hline 9 & 64 & 4 & 4 & 83.3 & 5438 & 8307 & 8214 & 1.70 & 66.2 \\
10 & 53 & 4 & 8 & 88.3 & 4773 & 5755 & 6722 & 2.13 & 71.0 \\
11 & 45 & 4 & 12 & 91.2 & 4186 & 4847 & 5660 & 2.50 & 73.9 \\
12 & 63 & 0 & 4 & 88.8 & 5706 & 10357 & 9129 & 1.81 & 62.5 \\
13 & 63 & 0 & 8 & 91.6 & 5886 & 9483 & 9352 & 1.74 & 62.9 \\
14 & 64 & 0 & 12 & 91.1 & 5947 & 9729 & 9749 & 1.82 & 61.0 \\
15 & 111 & 0 & 48 & 93.9 & 10631 & 19064 & 17659 & 1.82 & 60.2 \\
\hline
\end{tabular}

$[M] /[I]$ : molar ratio of TMC to ethanol, C\%: TMC conversion, $\alpha=\bar{M}_{\mathrm{n}, \mathrm{hh}} / \bar{M}_{\mathrm{n}, \mathrm{NMR}} \times 100 \%, \bar{M}_{\mathrm{n}, \mathrm{th}}=$ $[M] /[I] \cdot M W_{\mathrm{TMC}} \cdot$ Conversion\%, the amount of TMC: $1000 \mathrm{mg}$.

Table IV. The results of the ROP of TMC initiated by isopropanol

\begin{tabular}{cccccccccc}
\hline Run & $\begin{array}{c}{[M] /[I]} \\
(\mathrm{mol} / \mathrm{mol})\end{array}$ & $\begin{array}{c}\mathrm{TFA} \\
(\mu \mathrm{L})\end{array}$ & $\begin{array}{c}\text { Time } \\
(\mathrm{h})\end{array}$ & $\begin{array}{c}C \\
(\%)\end{array}$ & $\bar{M}_{\mathrm{n}, \mathrm{th}}$ & $\bar{M}_{\mathrm{n}, \mathrm{GPC}}$ & $\bar{M}_{\mathrm{n}, \mathrm{NMR}}$ & $\bar{M}_{\mathrm{w}} / \bar{M}_{\mathrm{n}}$ & $\begin{array}{c}\alpha \\
(\%)\end{array}$ \\
\hline 16 & 62 & 4 & 3 & 8.1 & 512 & 1922 & 1475 & 1.25 & 34.7 \\
17 & 68 & 4 & 4 & 12.1 & 839 & 2494 & 2328 & 1.32 & 36.1 \\
18 & 66 & 4 & 8 & 98.4 & 6624 & 18494 & 14368 & 1.68 & 46.1 \\
19 & 69 & 4 & 48 & 95.9 & 6749 & 15253 & 13337 & 1.96 & 50.6 \\
20 & 65 & 0 & 48 & 95.0 & 6298 & 35727 & 22654 & 1.69 & 27.8 \\
\hline \multicolumn{7}{l}{} \\
\hline$M] /[I]:$ molar ratio of TMC to isopropanol, C\%: TMC conversion, $\alpha=\bar{M}_{\mathrm{n}, \mathrm{th}} / \bar{M}_{\mathrm{n}, \mathrm{NMR}} \times 100 \%, \bar{M}_{\mathrm{n}, \mathrm{th}}=$
\end{tabular}

$[M] /[I]$ : molar ratio of TMC to isopropanol, C\%: TMC conversion, $\alpha=\bar{M}_{\mathrm{n}, \mathrm{th}} / \bar{M}_{\mathrm{n}, \mathrm{NMR}} \times 100 \%, \bar{M}_{\mathrm{n}, \mathrm{th}}=$ $[M] /[I] \cdot M W_{\mathrm{TMC}} \cdot$ Conversion\%, the amount of TMC: $1000 \mathrm{mg}$.

Table V. The results of the ROP of TMC initiated by tertiary butanol

\begin{tabular}{cccccccccc}
\hline Run & $\begin{array}{c}{[M] /[I]} \\
(\mathrm{mol} / \mathrm{mol})\end{array}$ & $\begin{array}{c}\text { TFA } \\
(\mu \mathrm{L})\end{array}$ & $\begin{array}{c}\text { Time } \\
(\mathrm{h})\end{array}$ & $\begin{array}{c}\mathrm{C} \% \\
(\%)\end{array}$ & $\bar{M}_{\mathrm{n}, \mathrm{th}}$ & $\bar{M}_{\mathrm{n}, \mathrm{GPC}}$ & $\bar{M}_{\mathrm{n}, \mathrm{NMR}}$ & $\bar{M}_{\mathrm{w}} / \bar{M}_{\mathrm{n}}$ & $\begin{array}{c}\alpha \\
(\%)\end{array}$ \\
\hline 21 & 60 & 4 & 3 & 16.7 & 1022 & 4100 & 2988 & 3.16 & 34.2 \\
22 & 63 & 4 & 4 & 17.5 & 1124 & 4047 & 3239 & 2.82 & 34.7 \\
23 & 64 & 4 & 8 & 91.3 & 5960 & 15075 & 12339 & 2.15 & 48.3 \\
24 & 65 & 4 & 48 & 87.7 & 5814 & 13041 & 11581 & 2.11 & 50.2 \\
25 & 68 & 0 & 48 & 94.3 & 6541 & 48605 & 39167 & 1.93 & 16.7 \\
\hline
\end{tabular}

$[M] /[I]$ : molar ratio of TMC to $t$-butanol, C\%: TMC conversion, $\alpha=\bar{M}_{\mathrm{n}, \mathrm{th}} / \bar{M}_{\mathrm{n}, \mathrm{NMR}} \times 100 \%, \bar{M}_{\mathrm{n}, \mathrm{th}}=$ $[M] /[I] \cdot M W_{\mathrm{TMC}} \cdot$ Conversion\%, the amount of TMC: $1000 \mathrm{mg}$.

and the product was dissolved in chloroform, followed by microfiltering through a $0.45-\mu \mathrm{m}$-pore membranes filter. The polymer was precipitated by the polymer solution being poured into an excess of cold diethyl ether, filtered and dried under vacuum until constant weight. Then the monomer conversion was determined gravimetrically.

\section{RESULTS AND DISCUSSION}

In our study, all the ROPs of TMC were performed in the melt bulk at $120^{\circ} \mathrm{C}$. The typical polymerization reaction time was $48 \mathrm{~h}$ to ensure monomer conversion as complete as possible. The degassing time after the addition of alcohol was fixed within $60 \mathrm{~s}$ at room temperature in order to reduce the loss of alcohol as much as possible. Benzyl alcohol was chosen as an initiator for the purpose of comparison with literature. ${ }^{18}$ Such alcohols as 1,4-butanediol, ethanol, isopropanol or $t$-butanol were selected as initiators in order to examine the effect of alcohol structure on the ROP of TMC.

\section{Characterization}

${ }^{1} \mathrm{HNMR}\left(\mathrm{CDCl}_{3}\right)$ for the product of benzyl alcohol initiated ROP of TMC: $\delta 1.90-1.93\left(\mathrm{CH}_{2} \mathrm{CH}_{2} \mathrm{OH}\right)$, 2.02-2.08 $\left(\mathrm{COOCH}_{2} \mathrm{CH}_{2}\right), 3.73\left(\mathrm{CH}_{2} \mathrm{CH}_{2} \mathrm{OH}\right), 4.24$ $\left(\mathrm{COOC} \underline{H}_{2}\right), 5.16\left(\mathrm{PhCH}_{2}\right), 7.35-7.37(\mathrm{Ph})$. No skeleton vibration of benzyl ring was observed in FTIR. This is because the amount of benzyl ring in the macromolecule is small. Both the spectra of ${ }^{1} \mathrm{HNMR}$ and FT IR were in good agreement with literature. ${ }^{18}$

${ }^{1} \mathrm{HNMR}$ from 1,4-butanediol-initiated ROP of TMC: $\delta$ 1.90-1.94 ( $\left.\mathrm{CH}_{2} \mathrm{CH}_{2} \mathrm{OH}\right), \quad 2.01-2.09$ $\left(\mathrm{COOCH}_{2} \mathrm{CH}_{2}\right), \quad 3.73 \quad\left(\mathrm{CH}_{2} \underline{\mathrm{CH}}_{2} \mathrm{OH}\right), \quad 4.24$ $\left(\mathrm{COOC} \underline{\mathrm{H}}_{2}\right) ;{ }^{1} \mathrm{H}$ NMR from ethanol-initiated ROP of TMC: $\delta$ 1.32( $\left.\mathrm{CH}_{3} \mathrm{CH}_{2} \mathrm{O}\right), 1.90-1.94\left(\mathrm{C}_{2} \mathrm{CH}_{2} \mathrm{OH}\right)$, 2.01-2.09 ( $\left.\mathrm{COOCH}_{2} \mathrm{CH}_{2}\right), \quad 3.73 \quad\left(\mathrm{CH}_{2} \underline{\mathrm{CH}}_{2} \mathrm{OH}\right)$, 4.24(COOC $\left.\mathrm{H}_{2}\right) ;{ }^{1} \mathrm{HNMR}$ from isopropanol-initiated ROP of TMC: $\delta$ 1.30 $\left(\mathrm{CH}_{3} \mathrm{CH}\left(\mathrm{CH}_{3}\right) \mathrm{O}\right), \quad 1.90-1.94$ 
$\left(\mathrm{CH}_{2} \mathrm{CH}_{2} \mathrm{OH}\right), \quad 2.01-2.09 \quad\left(\mathrm{COOCH}_{2} \mathrm{CH}_{2}\right), \quad 3.73$ $\left(\mathrm{CH}_{2} \mathrm{CH}_{2} \mathrm{OH}\right)$, 4.24( $\left.\mathrm{COOCH} \mathrm{H}_{2}\right)$; ${ }^{1} \mathrm{HNMR}$ from $t$ butanol-initiated ROP of TMC: $\delta \quad 1.28\left(\mathrm{CH}_{3} \mathrm{C}\right.$ $\left.\left(\mathrm{CH}_{3}\right)_{2} \mathrm{O}\right), \quad 1.90-1.94 \quad\left(\mathrm{CH}_{2} \mathrm{CH}_{2} \mathrm{OH}\right), \quad 2.01-2.09$ $\left(\mathrm{COOCH}_{2} \mathrm{CH}_{2}\right), 3.73\left(\mathrm{CH}_{2} \underline{\mathrm{CH}}_{2} \mathrm{OH}\right), 4.24\left(\mathrm{COOCH}_{2}\right)$.

The fragment peaks of alcohols as initiators were observed in NMR spectra. These peaks were assigned by reference to the ${ }^{1} \mathrm{HNMR}$ spectrum of diethyl carbonate and diisopropyl carbonate, respectively. The existence of these fragments in the polymers and the peaks of the proton of $\mathrm{CH}_{2}$ attached to the $\mathrm{OH}$ group at the chain end at $3.73 \mathrm{ppm}$ testified that the alcohol was the real initiator. No peaks at $3.40-3.46 \mathrm{ppm}$ in ${ }^{1} \mathrm{H}$ NMR appeared. The signal is assignable to methylene protons adjacent to an ether oxygen that would be formed from decarboxylation reaction. It was proved that no decarboxylation reaction took place under the experimental conditions.

The calculated molecular weight from ${ }^{1} \mathrm{H} N \mathrm{MR}$ was determined as follows:

$$
\bar{M}_{\mathrm{n}, \mathrm{NMR}}=\left(\frac{A_{4.24} / 2}{A_{3.73}}+1\right) \times M W_{\mathrm{TMC}},
$$

where $A_{4.24}$ and $A_{3.73}$ denote the integration intensities at $4.24 \mathrm{ppm}$ and $3.73 \mathrm{ppm}$ in the ${ }^{1} \mathrm{H}$ NMR spectra, respectively, and $M W_{\text {TMC }}$ denotes the molecular weight of monomer TMC. The calculated results are listed in Tables I to V.

\section{Synthesis}

Usually, an acidic catalyst is advantageous to the ring-opening reaction in Scheme 1. As comparison, experiments were done in the presence of or in the absence of TFA. All the reactions proceeded smoothly no matter whether TFA was added or not from the data of monomer conversion and molecular weight in Tables I $\sim$ V. The smooth ROP of TMC in the absence of TFA was attributed to the polymerization conditions of the melt bulk at $120^{\circ} \mathrm{C}$. This is because the higher polymerization temperature and the higher monomer concentration in bulk system reduced the induction period time and accelerated the polymerization. In contrast, the similar reaction proceeded difficultly in solution in the absence of TFA at $0^{\circ} \mathrm{C}$ or

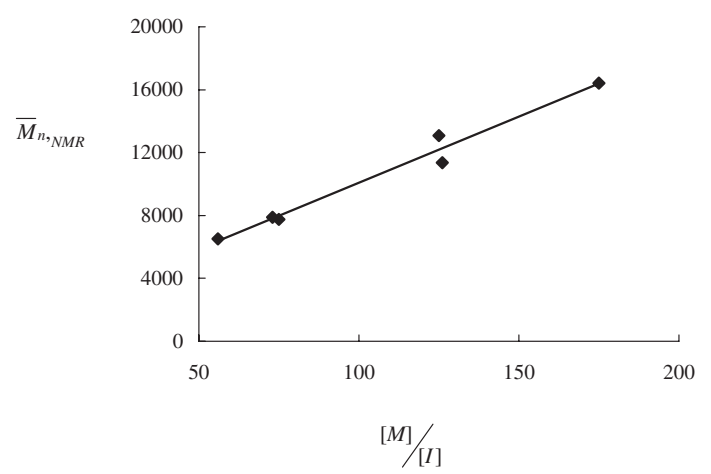

Figure 1. Dependence of $\bar{M}_{\mathrm{n}, \mathrm{NMR}}$ on the molar ratio of TMC over 1,4-butanediol with or without TFA catalyst in melt bulk at $120^{\circ} \mathrm{C}$.

$50^{\circ} \mathrm{C}$, with very low conversion of monomer. ${ }^{18}$ As can be seen, TFA is not indispensable in the ROP under the above polymerization conditions.

For the ROP initiated by 1,4-butanediol, the results are listed in Table II. From Table II, TMC monomer can be almost completely consumed within the predetermined reaction time, independent of both the $[M] /[I]$ ratio and TFA catalyst. We complied the molecular weights in Table II together in Figure 1. These data lay in a common line whether using TFA or not. It is shown that the number-average molecular weights $\left(\bar{M}_{\mathrm{n}, \mathrm{NMR}}\right)$ linearly increased with the $([M] /[I])$. In addition, the molecular weights determined from NMR were very close to the theoretical molecular weights $\quad\left(\bar{M}_{\mathrm{n}, \mathrm{th}}=[M] /[I] \cdot M W_{\mathrm{TMC}}\right.$. Conversion\%). This indicated that almost all the alcohol participated in the ROP and the alcohol was a real initiator, and that the molecular weights of the polymers can be accurately predicted by the molar ratio of monomer to initiator and the monomer conversion. These observations show that this reaction conformed to the pseudoliving polymerization.

According to a pseudoliving polymerization, the theoretical molecular weights $\bar{M}_{\mathrm{n}, \mathrm{th}}=[M] /[I]$. $M W_{\mathrm{TMC}} \cdot$ Conversion\% should be close to the $\bar{M}_{\mathrm{n}, \mathrm{NMR}}$. However, the $\bar{M}_{\mathrm{n}, \mathrm{NMR}}$ was commonly higher than the expected $\bar{M}_{\mathrm{n}, \mathrm{th}}$ in ethanol, isopropanol or $t$ butanol initiated ROP. In order to discuss easily, a parameter was defined:

$$
\alpha=\bar{M}_{\mathrm{n}, \mathrm{th}} / \bar{M}_{\mathrm{n}, \mathrm{NMR}} \times 100 \%=\frac{([M] /[I])_{\text {feed }} \cdot M W_{\mathrm{TMC}} \cdot C \%}{([M] /[I])_{\mathrm{polymer}} \cdot M W_{\mathrm{TMC}}}=\frac{([M] /[I])_{\text {feed }} \cdot M W_{\mathrm{TMC}} \cdot C \%}{\left([M]_{\mathrm{feed}} \cdot C \% /[I]_{\mathrm{polymer}}\right) \cdot M W_{\mathrm{TMC}}}=\frac{[I]_{\mathrm{polymer}}}{[I]_{\mathrm{feed}}}
$$

where $[I]_{\text {polymer }}$ denotes the amount of the alcohol initiator which practically participates in the polymerization reaction, and $[I]_{\text {feed }}$ denotes the total amount of the fed alcohol. So $\alpha$ also means the ratio of the alcohol participating in the polymerization to the fed alcohol. If the $\alpha$ were less than 1 , it would be meant that part of the fed alcohol does not participate in the polymerization or is lost.

In Table II, the $\alpha$ values were in the range of $85 \%$ and $110 \%$, and it can be deduced that almost all the primary $\mathrm{OH}$ groups of 1,4-butanediol initiated ROP. But the $\alpha$ values fell in the range of $60.2 \%$ and 
$73.9 \%$ in Table III, lower than $100 \%$. The low $\alpha$ values were explained by partial evaporation of ethanol during the degassing procedure before sealing the polymerization tube, whereas 1,4-butanediol was lost less due to a lower volatility.

In the case of isopropanol initiated ROP in the presence of TFA, the $\alpha$ values were in the range of $34.7 \%$ and $50.6 \%$ (Table IV), further lower than the values for ethanol. Of course, the evaporation loss of iso propanol also existed, but the loss should not go beyond the level for ethanol in terms of boiling point and volatility under the fixed operation conditions. In fact, because a secondary $\mathrm{OH}$ group has a poorer initiation ability compared with a primary $\mathrm{OH}$ group, when the secondary $\mathrm{OH}$ group of isopropanol was transformed into primary $\mathrm{OH}$ group in the process of ROP, the rest of isopropanol had less chance to participate in the initiation step. As a result, part of isopropanol did not participate in the ROP so the $\alpha$ was lower. In the absence of TFA, the secondary $\mathrm{OH}$ group was more difficult to initiate the ROP, so a lower $\alpha$ value was observed (27.8\% in run 20 ). The similar result was drawn out for $t$-butanol as an initiator (in Table V).

So the $\alpha$ can be used as a guide for judging the initiation ability of alcohol. The lower the $\alpha$ value, the lower the initiation ability of alcohol based on the similar or lower evaporation loss of alcohol. Thus isopropanol and $t$-butanol had a poorer initiation ability than ethanol with or without TFA.

In the absence of TFA, the $\alpha$ value for $t$-butanol $(16.7 \%$, run 25$)$ is lower than for isopropanol $(27.8 \%$, run 20$)$. So $t$-butanol had an even lower reactivity than isopropanol considering the similar or even lower evaporation loss of $t$-butanol under the same reaction operation.

According to the $\alpha$ values, a conclusion can be drawn that the participating degrees of isopropanol and $t$-butanol in the ROP were very low and that the ability orders to initiate the ROP are: (1) ethanol > isopropanol $>t$-butanol in the absence of TFA, (2) in the presence of TFA, ethanol was higher than isopropanol and $t$-butanol, but isopropanol and $t$-butanol was difficult to order only by using the $\alpha$ value. The difference of the reactivity seems to come from the steric hindrance.

More attention, the reaction still conformed to the pseudoliving polymerization. Preciously speaking, the predicted molecular weight should be revised as follows:

$$
\bar{M}_{\mathrm{n}}=\frac{[M]}{[I] \cdot \alpha} \cdot M W_{\mathrm{TMC}} \cdot \text { Conversion } \%
$$

where the $[I] \cdot \alpha$ denotes the amount of the initiator practically participating in the ROP.
The monomer conversion reached $83.3 \%$ (run 9) or $88.8 \%$ (run 12) for ethanol as an initiator in the presence of or in the absence of TFA for $4 \mathrm{~h}$ reaction time, respectively. In contrast, the conversion with isopropanol or $t$-butanol as an initiator in the presence of TFA was at a low level for $4 \mathrm{~h}$ reaction time, only $12.1 \%$ (run 17) or $17.5 \%$ (run 22), respectively. Clearly, there was a longer induction period for isopropanol or $t$-butanol than for ethanol initiation. After the next $4 \mathrm{~h}$ the monomer conversions showed a quick increase and reached a high level of more than $90 \%$ (run 18 and run 23). The quick increase can be explained as follows: over an induction period, the $s e c-$ or $t-\mathrm{OH}$ was gradually transformed into a primary $\mathrm{OH}$ attached to the chain end according to the reaction equation. Commonly, a primary $\mathrm{OH}$ has higher reaction activity compared with a sec-or $t$-OH due to lower steric hindrance. And the resulting primary $\mathrm{OH}$ end group became the new initiator center. Afterwards, the reaction was similar with the reaction by ethanol initiation. This also demonstrated that isopropanol and $t$-butanol had a poorer initiation ability than ethanol in the presence of TFA.

Molecular weight distribution (MWD $=\bar{M}_{\mathrm{w}} / \bar{M}_{\mathrm{n}}$ ) is also a guide for initiation ability. MWD increased with reaction time with ethanol or isopropanol as an initiator but decreased with $t$-butanol as an initiator. At the initial stage, once a little of $t$-butanol lighted up the ring-opening reaction of TMC under the environment of high monomer concentrations despite the poor initiation ability of $t$-butanol, the $t$-OH was transformed into a primary $\mathrm{OH}$. Afterwards, the primary $\mathrm{OH}$ dominated the ROP due to its low steric hindrance. If the rest of $t$-butanol initiated the ROP, the reaction should pass a long induction period again and produce polymers with a lower molecular weight. Thus the MWD was wide. With the process of reaction, the system became viscous and the longer molecule moved more slowly and propagated more difficultly. The MWD tended narrower again. However, the transformation of the kind of hydroxyl group did not exist for ethanol initiation. So the value of MWD is also a guide for initiation ability. From here, the initiation ability of $t$-butanol is poorer than of ethanol and isopropanol in the presence of TFA.

\section{Mechanism}

A plausible reaction process of the ROP of TMC initiated by an alcohol in solution has been proposed, ${ }^{18}$ illustrated in Scheme 2. We think a similar process dominate the melt bulk ROP. The carbonyl carbon of TMC may be attacked by the oxygen of the alcohol, followed by a ring-opening. Under acidic environment, the carbonyl carbon carries more positive charges, which favors the attack of the oxygen atom 

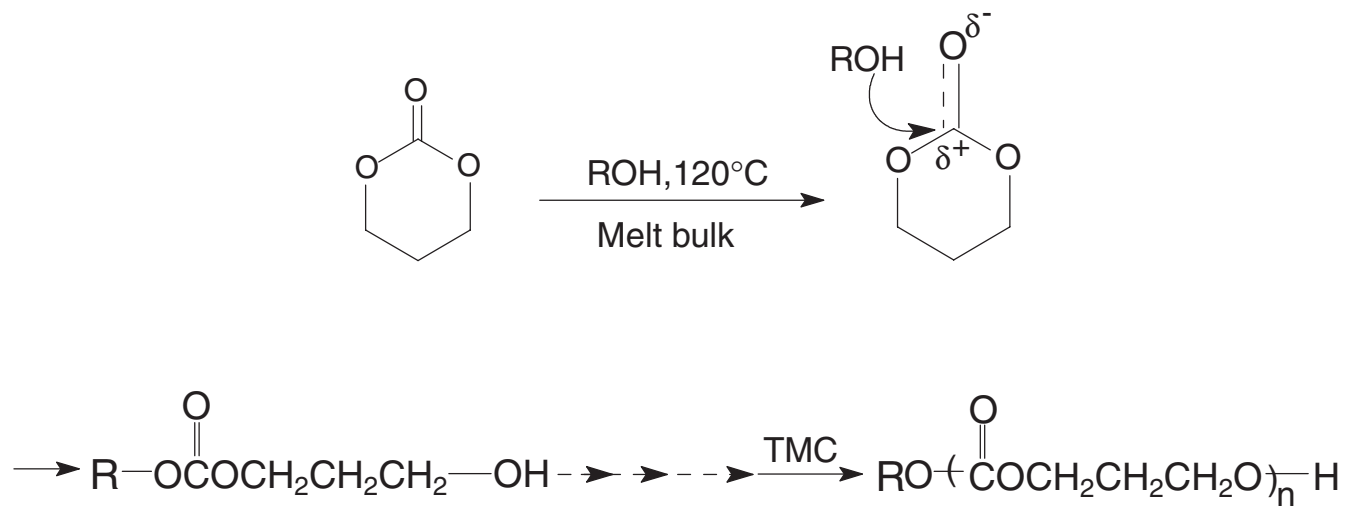

Scheme 2. Mechanism of ROP of TMC initiated by alcohol in melt bulk system.

in the initiator alcohol, resulting in a faster polymerization. At this time, the steric hindrance of alcohols was easily evened up. And thus, in the presence of TFA, the ability order is more difficult to discriminate.

\section{REFERENCES}

1. K. J. Zhu, R. W. Hendren, K. Jensen, and C. G. Pitt, Macromolecules, 24, 1736 (1991).

2. A. C. Albertsson and M. Eklund, J. Appl. Poly. Sci., 57, 87 (1995).

3. F. Q. Yu and R. X. Zhuo, Polym. J., 35, 671 (2003).

4. C. M. Dong, K. Y. Qiu, Z. W. Gu, and X. D. Feng, Polymer, 42, 6891 (2001).

5. I. Arvanitoyannis, A. Nakayama, N. Kawasaki, and N. Yamamoto, Polymer, 36, 2271 (1995).

6. D. K. Han and J. A. Hubbell, Macromolecules, 29, 5233 (1996).

7. S. H. Lee, S. H. Kim, Y. K. Han, and Y. H. Kim, J. Polym. Sci., Part A: Polym. Chem., 39, 973 (2001).

8. S. J. de Jong, E. R. Arias, D. T. S Rijkers, C. F. van Nostrum, J. J. Kettenes-van den Bosch, and W. E. Hennink, Polymer, 42, 2795 (2001).

9. P. J. A IN'T Veld, E. M. Velner, P. V. D. Witte, J. Hamhuis,
P. J. Dijkstra, and J. Feijen, J. Polym. Sci., Part A: Polym. Chem., 35, 219 (1997).

10. T. Shiomi, K. Imai, K. Takenaka, H. Takeshita, H. Hayashi, and Y. Tezuka, Polymer, 42, 3233 (2001).

11. J. K. Kim, D. J. Park, M. S. Lee, and K. J. Ihn, Polymer, 42, 7429 (2001).

12. D. W. Lim and T. G. Park, J. Appl. Polym. Sci., 75, 1615 (2000).

13. H. R. Kricheldorf, I. Krieiser-Saunders, and C. Boettcher, Polymer, 36, 1253 (1995).

14. X. Zhang, D. A. McDonald, M. F. A. Goosen, and K. B. M. Cauley, J. Polym. Sci., Part A: Polym. Chem., 32, 2965 (1994).

15. A. J. Nijenhuis, D. W. Grijpma, and A. J. Pennings, Macromolecules, 25, 6419 (1992).

16. A. Kowalski, A. Duda, and S. Penczek, Macromolecules, 33, 689 (2000).

17. H. R. Kricheldorf, C. Boettcher, and K. U. Tonnes, Polymer, 33, 2817 (1992).

18. J. Matsuo, S. Nakano, F. Sanda, and T. Endo, J. Polym. Sci., Part A: Polym. Chem., 36, 2463 (1998).

19. T. Ariga, T. Takata, and T. Endo, J. Polym. Sci., Part A: Polym. Chem., 31, 581 (1993). 